Article

\title{
Direct Potentiometric Study of Cationic and Nonionic Surfactants in Disinfectants and Personal Care Products by New Surfactant Sensor Based on 1,3-Dihexadecyl-1H-benzo[d]imidazol-3-ium
}

\author{
Nikola Sakač ${ }^{1, *}$, Dean Marković ${ }^{2}$ D, Bojan Šarkanj ${ }^{3}$ D, Dubravka Madunić-Čačić ${ }^{1,4}$, Krunoslav Hajdek ${ }^{5}$, \\ Božo Smoljan ${ }^{5}$ and Marija Jozanović ${ }^{6, *}$ \\ 1 Faculty of Geotechnical Engineering, University of Zagreb, 42000 Varaždin, Croatia; \\ dubravka.madunic-cacic@saponia.hr \\ 2 Department of Biotechnology, University of Rijeka, 51000 Rijeka, Croatia; dean.markovic@biotech.uniri.hr \\ 3 Department of Food Technology, University North, 48000 Koprivnica, Croatia; bsarkanj@unin.hr \\ 4 Saponia Chemical, Pharmaceutical and Foodstuff Industry, Inc., 31000 Osijek, Croatia \\ 5 Department of Packaging, Recycling and Environmental Protection, University North, 48000 Koprivnica, \\ Croatia; krunoslav.hajdek@unin.hr (K.H.); bozo.smoljan@unin.hr (B.S.) \\ 6 Department of Chemistry, University of Osijek, 31000 Osijek, Croatia \\ check for \\ updates \\ * Correspondence: nikola.sakac@gfv.unizg.hr (N.S.); mjozanovic@kemija.unios.hr (M.J.); \\ Tel.: +385-915830336 (N.S.); +385-996865716 (M.J.)
}

Citation: Sakač, N.; Marković, D.; Šarkanj, B.; Madunić-Čačić, D.; Hajdek, K.; Smoljan, B.; Jozanović, M. Direct Potentiometric Study of Cationic and Nonionic Surfactants in Disinfectants and Personal Care Products by New Surfactant Sensor Based on 1,3-Dihexadecyl-1Hbenzo[d]imidazol-3-ium. Molecules 2021, 26, 1366. https://doi.org/ 10.3390/molecules26051366

Academic Editors: Maria Celeiro and Maria Llompart

Received: 27 January 2021

Accepted: 26 February 2021

Published: 4 March 2021

Publisher's Note: MDPI stays neutral with regard to jurisdictional claims in published maps and institutional affiliations.

Copyright: () 2021 by the authors Licensee MDPI, Basel, Switzerland. This article is an open access article distributed under the terms and conditions of the Creative Commons Attribution (CC BY) license (https:// creativecommons.org/licenses/by/ $4.0 /)$.

\begin{abstract}
A novel, simple, low-cost, and user-friendly potentiometric surfactant sensor based on the new 1,3-dihexadecyl-1H-benzo[d]imidazol-3-ium-tetraphenylborate (DHBI-TPB) ion-pair for the detection of cationic surfactants in personal care products and disinfectants is presented here. The new cationic surfactant DHBI-Br was successfully synthesized and characterized by nuclear magnetic resonance (NMR), Fourier transform infrared (FTIR) spectrometry, liquid chromatography-mass spectrometry (LC-MS) and elemental analysis and was further employed for DHBI-TPB ion-pair preparation. The sensor gave excellent response characteristics for CTAB, CPC and Hyamine with a Nernstian slope (57.1 to $59.1 \mathrm{mV} /$ decade) whereas the lowest limit of detection (LOD) value was measured for CTAB $\left(0.3 \times 10^{-6} \mathrm{M}\right)$. The sensor exhibited a fast dynamic response to dodecyl sulfate (DDS) and TPB. High sensor performances stayed intact regardless of the employment of inorganic and organic cations and in a broad $\mathrm{pH}$ range $(2-11)$. Titration of cationic and etoxylated (EO)-nonionic surfactant (NSs) (in $\mathrm{Ba}^{2+}$ ) mixtures with TPB revealed the first inflexion point for a cationic surfactant and the second for an EO-nonionic surfactant. The increased concentration of EO-nonionic surfactants and the number of EO groups had a negative influence on titration curves and signal change. The sensor was successfully applied for the quantification of technical-grade cationic surfactants and in 12 personal care products and disinfectants. The results showed good agreement with the measurements obtained by a commercial surfactant sensor and by a two-phase titration. A good recovery for the standard addition method (98-102\%) was observed.
\end{abstract}

Keywords: cationic surfactants; disinfectants; ionophore; nonionic surfactants; nose drops; personal care products; potentiometry; sensor

\section{Introduction}

Surfactants, or surface-active agents, lower the surface tension of water. A surfactant's basic structure is a charged, hydrophilic head and a "fat" hydrophobic tail [1]. Based on the charge of the head, they are divided into anionic, cationic, amphoteric and nonionic categories. Surfactants are widely used as washing and cleaning agents. The market size for surfactants was US\$39.901 million in 2019 and is projected to reach US\$52.417 million by 2025, at a compound annual growth rate (CAGR) of 4.5\% between 2020 and 2025 [2]. 
Cationic surfactant production remains at $6 \%$ of the global surfactant industry. They are used as disinfectants, bactericides, corrosion inhibitors and cleaning agents in home products and professional products in hospitals, industry, and agronomy as well as oilfield chemicals. The positively charged head of CSs allows them to stick to negatively charged surfaces, preventing electrostatic repulsion and act as textile softeners. Nonionic surfactants are amphipathic molecules that contain a lipophilic part, usually long alkyl chain or fatty acid, and a hydrophilic part such as an ethylene oxide chain of varying length, which means they are nonionizable in water [3]. Nonionic surfactants enhance the cleaning properties of cationic surfactants [4]. Formulations of cationic with nonionic surfactants are common in personal care products and pharmaceuticals [5,6].

Because of the global COVID-19 pandemic crisis, rising of world population, and the increasing industrialization of developing countries, the market demand for personal care products, disinfectants, detergents and cleaning agents is continuously growing [7]. The misuse and overuse of disinfectants as a result of heightened concerns regarding SARSCoV-2 transmission through the skin or via environmental surfaces may have adverse effects on the skin or reproductive and respiratory systems [8]. Moreover, occupational exposure to quaternary ammonium compounds found in disinfectants are linked to increased risks associated with adverse respiratory conditions such as asthma, pulmonary cell damage and inflammation [9]. Consequently, in addition to many positive benefits, cationic surfactants may have a varied negative impact on human health and the environment $[10,11]$. Thus, new, fast, sensitive, and affordable methods of cationic surfactant determination in environmental samples and the quality control of commercial product formulations containing cationic surfactants are highly needed and have to be urgently developed. The regularly employed classical method for cationic surfactant determination is based on a two-phase titration with colorimetric signal change [12]. Even though the method has been recently improved [13], it has many drawbacks such as requiring the use of hazardous organic solvents or the need for experienced personnel and precise determination of errors for optical end-point readout.

Several new methods of detecting cationic surfactants based on luminescence [14], solid phase extraction-ion chromatography with conductivity detection [15], and fluorescence [16] have recently been established. However, because of complexity, increased price, or poor reproducibility, they are not suitable for routine analysis. On the other hand, taking into account their simplicity, speed, cost, reproducibility and usability as a routine analysis technique, ion-selective surfactant sensors for direct potentiometric titrations have been more and more considered as appropriate substitutions for the classical two-phase titrations and other methods.

Most surfactant sensors possess a liquid membrane-type sensor composed of an ionophore, a high molecular weight PVC, and a plasticizer $[17,18]$. The ionophore is the sensing material and is usually responsible for the selective interaction with the surfactant counter-ion and for the formation of the ion-pair. The ideal ionophore should have certain properties, including high stability and very low solubility, which further leads to the high sensitivity and increased changes of the potential in the inflexion point [18]. Therefore, the development of the new ionophores is of the high interest in order to enhance the electroanalytical properties of surfactant electrodes.

One of the possible major drawbacks of ion-selective surfactant electrodes could be the leaching of the sensor material that may result in their reduced lifetime [19]. The employment of low water-soluble hydrophobic ionophores can reduce leaching and enhance sensor properties. Recently, our group [20] and others [21] showed that the use of carbon-based nanomaterials in surfactant sensoring may lead to the significant enhancement of electrode properties as well as to a reduced cost of sensor fabrication. However, although the implementation of carbon nanotubes (CNTs) in electrochemical sensors has been shown to enhance some sensor functions, such as signal stability and lifetime, the strong interactions between inherently insoluble CNTs and polar solvents make these 
materials a challenge for the surfactant sensing [22]. Therefore, the development of new sensing materials and ionophores is highly desirable.

One ionophoric alternative is the preparation and use of new long-chain quaternary ammonium salts with high amphipathic character. It could improve sensor characteristics as well as ameliorate chemical interaction and recognition in ionophore binding sites [23], which depend on a sensitive balance between rigidity, required for selectivity, and flexibility, necessary for fast sensor response. The aromatic quaternary ammonium salts possess the required rigidity due to their aromatic rings as well as flexibility, because of free rotation around the exocyclic $\mathrm{C}-\mathrm{N}$ bonds and within alkyl substituents.

The study of cationic surfactants in commercial product formulations where nonionic surfactants are present, represents an analytical challenge since nonionic surfactants have a negative influence on the direct potentiometric determination of cationic surfactants [24,25]. For this reason, it is important to investigate their influence on direct potentiometric titrations of cationic surfactants at different concentration levels and on different numbers of ethoxylated (EO) groups [26]. Apart from our group [25], several other studies developed direct potentiometric sensors for cationic surfactants $[10,21,27]$, and some created mathematical models to predict the end-point break potential values [28].

The aim of this paper was to develop a novel direct potentiometric surfactant sensor based on the new 1,3-dihexadecyl-1H-benzo[d]imidazol-3-ium (DHBI) ionophore implemented as a DHBI-TPB sensing material in a PVC-based sensing membrane. Thus, the obtained novel DHBI-TPB surfactant sensor was fully characterized by analytical methods and further employed for the quantifications of cationic surfactants. The latter was performed by direct potentiometric titrations in model samples containing cationic and nonionic surfactants with different degrees of ethoxylation and in personal care products and disinfectants.

\section{Results and Discussion}

\subsection{Synthesis and Characterization of the Quaternary Alkyl Ammonium Salt 2}

As shown in Scheme 1, quaternary alkyl ammonium salt DHBI-Br 1 was synthesized by the reaction of $1 H-1,3$-benzimidazole and 1-bromohexadecane. The reaction yield was established as $62.7 \%$. The structure of the synthesized compound 1 was confirmed by IR, ${ }^{1} \mathrm{H}$ - and ${ }^{13} \mathrm{C}-\mathrm{NMR}$ spectroscopy, mass spectrometry and elemental analysis (Supplementary Material, Figures S1-S4) established as 62.7\%. The structure of synthesized compound 1 was confirmed by IR, 1H- and 13C-NMR spectroscopy, mass spectrometry and elemental analysis (Supplementary Material, Figures S1-S4).
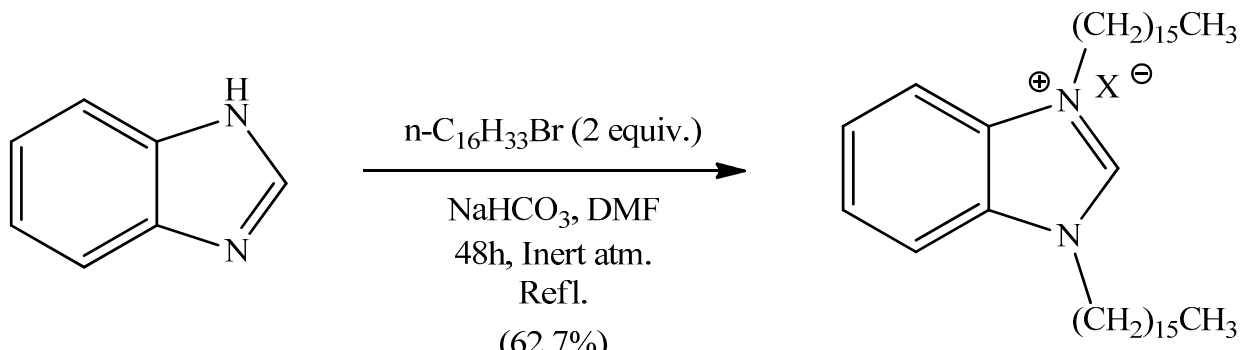

$\begin{array}{ll}\text { HDBI-Br, 1: } X=\mathrm{Br} & \text { NaTPB } \\ \text { EtOH/H } / \mathrm{H}_{2} \mathrm{O}\end{array}$

Scheme 1. Synthesis of DHBI-TPB ion-pair sensing complex 2 via quaternary alkyl ammonium salt 1,3-dihexadecyl-1 $H$ benzo[d]imidazol-3-ium bromide (1).

\subsection{Sensor Characteristics}

After DHBI-Br 1 was synthesized, the counter ion exchange to obtain the ionophore 2 was performed by the controlled reaction of DHBI and a TPB (Scheme 1). The DHBITPB ionophore 2 was purified and incorporated into the PVC-based liquid-ion sensor 
membrane, which was then implemented into the Phillips ISE body electrode and used as a surfactant sensor for further investigations.

\subsubsection{Response}

Response characteristics of the newly developed DHBI-TPB surfactant sensor were studied through the repetitive series of 5 cycles employing commercially available cationic surfactants regularly used in pharmaceutical and daily-care products as well as disinfectant formulations.

Generally, the direct potentiometric electromotive force of the cationic surfactant sensor with an ion-pair ionophore is based on the modified Nernstian equation:

$$
E=E_{0}+S \log a_{S C a t^{+}}
$$

where $E$ is the electromotive force of the surfactant sensor; $E_{0}$ is the constant potential term of the system; $S$ is the slope of direct potentiometric surfactant sensor; $\mathrm{SCat}^{+}$is the activity of the positively charged surfactant ion.

The response of the DHBI-TPB surfactant sensor was studied for three typical cationic surfactants: hexadecyltrimethylammonium (CTAB), cetylpyridinium chloride (CPC) and Hyamine. Direct potentiometric response curves for each cationic surfactant were elaborated by MS Excel using a linear regression analysis to calculate the statistical data for the response characteristics of the DHBI-TPB surfactant sensor. Data were calculated for the 5repetition cycle and slope values, intercept, correlation coefficient, limit of detection (LOD) and a useful concentration range for $\mathrm{CTAB}, \mathrm{CPC}$ and Hyamine were measured, as shown in Table 1. The DHBI-TPB surfactant sensor showed excellent response characteristics for all three selected surfactants with a Nernstian slope; $59.2 \mathrm{mV} /$ decade (CTAB), $58.4 \mathrm{mV} /$ decade (CPC), $57.1 \mathrm{mV} /$ decade (Hyamine), respectively. All three surfactants exhibited a high correlation coefficient in the effective linear concentration range. The broadest useful linear concentration range was achieved for CTAB, $2.0 \times 10^{-6}$ to $1.0 \times 10^{-4} \mathrm{M}$, and the lowest LOD value was acquired for same surfactant, $0.3 \times 10^{-6} \mathrm{M}$, respectively. Both, CPC and Hyamine exhibited a useful linear concentration range from $3.0 \times 10^{-6}$ to $1.0 \times 10^{-4} \mathrm{M}$, slightly lower than for CTAB. In general, the DHBI-TPB surfactant sensor was exploited daily, and it exhibited an enhanced durability and signal stability over more than 4 months.

Table 1. Calculated response characteristics for the DHBI-TPB surfactant sensor to CTAB, CPC and Hyamine cationic surfactants with mean values at $\pm 95 \%$ confidence limits.

\begin{tabular}{lccc}
\hline Parameters & CTAB & CPC & Hyamine \\
\hline Slope $(\mathrm{mV} /$ decade) & $59.2 \pm 0.5$ & $58.4 \pm 0.7$ & $57.1 \pm 1.1$ \\
Correlation coefficient $\left(\mathrm{R}^{2}\right)$ & 0.9999 & 0.9992 & 0.9988 \\
Intercept $(\mathrm{mV})$ & $159.1 \pm 7.0$ & $199.6 \pm 7.2$ & $174.0 \pm 5.1$ \\
Detection limit $(\mathrm{M})$ & $0.3 \times 10^{-6}$ & $0.7 \times 10^{-6}$ & $1.1 \times 10^{-6}$ \\
Useful linear concentration range $(\mathrm{M})$ & $2.0 \times 10^{-6}$ to $1.0 \times 10^{-4}$ & $3.0 \times 10^{-6}$ to $1.0 \times 10^{-4}$ & $3.0 \times 10^{-6}$ to $1.0 \times 10^{-4}$ \\
\hline
\end{tabular}

\subsubsection{Dynamic Response}

Upon establishment of the response characteristic of the DHBI-TPB surfactant sensor towards cationic surfactants, a dynamic response on two selected anions--an organoboronTPB and a dodecyl sulfate (DDS) - was measured. The dynamic response was evaluated by adding corresponding quantities of the TPB and DDS anions into deionized water in a broad concentration range from $1 \times 10^{-6}$ to $1 \times 10^{-3} \mathrm{M}$. The behavior of the DHBI-TPB surfactant sensor towards the affinity of TPB and DDS anions was observed (Figure 1) in terms of response time and signal stability. For both anions, the DHBI-TPB surfactant sensor had a fast response time (within few seconds) and fast signal stabilization even at low concentrations. The dynamic response study of the DHBI-TPB surfactant sensor towards the addition of TPB and DDS anions was used to predict the characteristics of direct potentiometric titration curves in terms of the change of sharpness of the signal 
and clarity of the inflexion point, which have a positive impact on sensor sensitivity and accuracy in end-point detection.

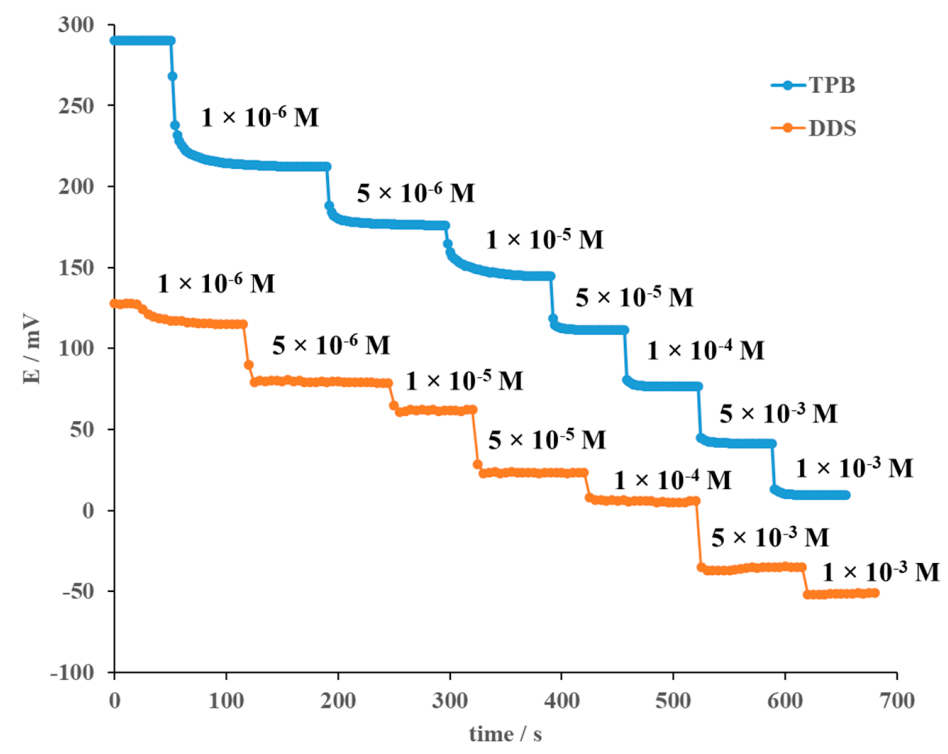

Figure 1. Dynamic response characteristics of the DHBI-TPB surfactant sensor towards TPB and DDS anions established by the addition of a determined concentration of selected anions.

\subsubsection{Interferences}

To characterize the DHBI-TPB surfactant sensor fully, an interference study was performed. Several inorganic and organic cations commonly present in commercial products formulations were used as potentially interfering ions. To verify the potential interferences, the CTAB cationic surfactant was selected since it gave the best response values and was cheaper than CPC. To calculate the selectivity coefficients for corresponding cations, the response of CTAB (10 $\mu \mathrm{M}$ to $10 \mathrm{mM})$ was measured in the interfering cation solution $(20 \mathrm{mM})$. The influence of the interfering cation on the DHBI-TPB surfactant sensor response may be described by the Nikolskii-Eisenman equation. For the calculation of the selectivity coefficients $\left(K_{S C a t}^{\text {pot }} t_{\text {determinated analyte ion }}^{+} S C a t_{\text {interf fering ion }}^{+}\right.$or shorter $\left.K_{S C a t_{d e t .}^{\text {pot }}}^{\text {pCat }}{ }_{\text {int. }}^{+}\right)$a fixed interference method proposed by IUPAC [27] was used, and the calculated values are presented in Table 2. As shown, none of the investigated interferents had a significant influence on the DHBI-TPB surfactant sensor response towards CTAB.

Table 2. Calculated selectivity coefficient for different inorganic and organic anions mostly used in commercially formulated products measured with the DHBI-TPB surfactant sensor.

\begin{tabular}{lc}
\hline $\begin{array}{l}\text { Interfering } \\
\text { Cations }\end{array}$ & $\boldsymbol{K}_{\text {Cat }}^{\text {pot }}$ \\
\hline $\mathrm{Na}^{+}$ & $4.1 \times 10^{-5}$ \\
$\mathrm{~K}^{+}$ & $2.5 \times 10^{-5}$ \\
$\mathrm{NH}_{4}^{+}$ & $6.2 \times 10^{-5}$ \\
$\mathrm{Mg}^{2+}$ & $3.6 \times 10^{-5}$ \\
$\mathrm{Ca}^{2+}$ & $1.6 \times 10^{-5}$ \\
$\mathrm{Zn}^{2+}$ & $2.7 \times 10^{-5}$ \\
2 -aminoethanol & $0.3 \times 10^{-5}$ \\
Tris(2-hydroxyethyl)amine & $1.1 \times 10^{-5}$ \\
Tetraethylazanium & $2.8 \times 10^{-5}$ \\
Triton B & $1.5 \times 10^{-5}$ \\
Benzyltriethylammonium & $5.2 \times 10^{-5}$ \\
\hline
\end{tabular}




\subsubsection{Influence of $\mathrm{pH}$}

Since personal care products and disinfectants differ in their $\mathrm{pH}$ values, a study of the influence of $\mathrm{pH}$ on the DHBI-TPB surfactant sensor was carried out. The study was performed by the addition of the solutions of $\mathrm{NaOH}$ and $\mathrm{HCl}$ in the $\mathrm{CTAB}$ solution $(0.5 \mathrm{mM})$ to adjust the $\mathrm{pH}$ from 2 to 13 . To examine the effect of the increased ionic strength, the identical procedure was repeated with a mixture of CTAB $(0.5 \mathrm{mM})$ in $\mathrm{Na}_{2} \mathrm{SO}_{4}(0.1 \mathrm{M})$. The potential readings of the potential stayed within $\pm 1 \mathrm{mV}$. As presented in Figure 2, there is no significant influence of the $\mathrm{pH}$ on the response of the DHBI-TPB surfactant sensor within a broad $\mathrm{pH}$ range for both, low and high ionic strengths. The latter might be important because a single surfactant sensor could be used to test various commercial samples of different $\mathrm{pH}$ values with extraordinary simplicity and universality.

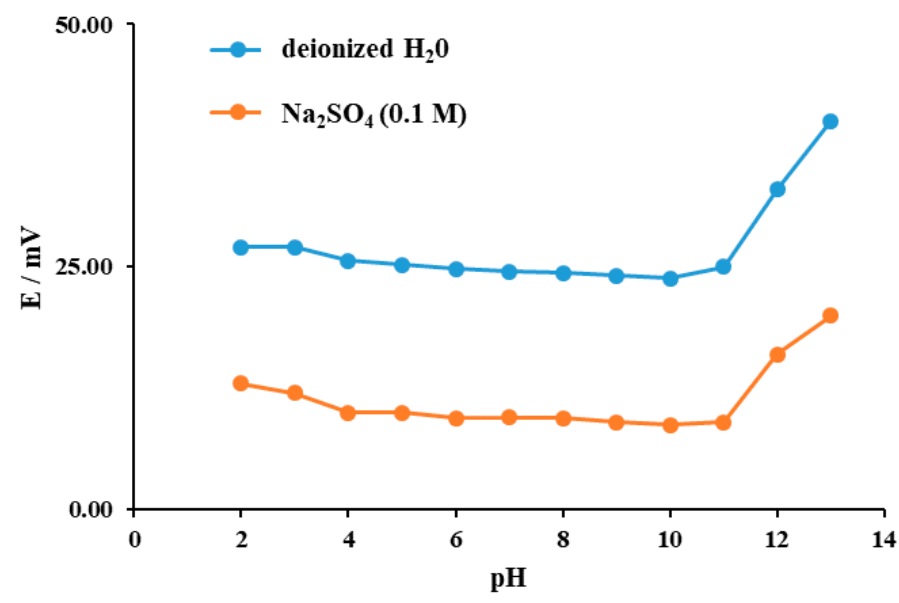

Figure 2. The study of the $\mathrm{pH}$ influence on the DHBI-TPB surfactant sensor response towards (1) hexadecyltrimethylammonium bromide $(\mathrm{CTAB})(0.5 \mathrm{mM})$ in deionized water and (2) CTAB $(0.5 \mathrm{mM})$ in $\mathrm{Na}_{2} \mathrm{SO}_{4}(0.1 \mathrm{M})$.

\subsection{Potentiometric Titration}

Since the DHBI-TPB surfactant sensor showed excellent response characteristics towards both TPB and DDS anions, direct potentiometric titrations of cationic surfactants were performed in two directions. For the first, the influence of nonionic surfactants and number of EO groups on direct potentiometric titrations, was examined by using TPB for the direct potentiometric titrations of CTAB and mixtures of $\mathrm{CTAB}$ with three different nonionic surfactants in the solution of $\mathrm{Ba}^{2+}$ salt. For the second, DDS was used for direct potentiometric titrations of commercial disinfectants and personal care products containing cationic surfactants, and the results obtained by the newly developed method with DHBITPB surfactant sensor were compared with the measurements obtained by the standard addition method.

\subsubsection{Titration of Model Samples Containing Cationic Surfactant and EO-Nonionic Surfactant}

Disinfectants and personal care products often have formulations consisting of cationic and nonionic surfactants. Whereas the role of a cationic surfactant is to clean, disinfect or preserve, the major role of the nonionic surfactants is to provide better performance of the final formulations and because cationic surfactants are incompatible with anionic surfactants [4].

Direct potentiometric titrations of the cationic surfactant $\mathrm{CTAB}$ with the anionic titrant TPB can be described in two steps. First step is the formation of an ion pair:

$$
\mathrm{CTAB}^{+}+\mathrm{TPB}^{-} \Leftrightarrow \mathrm{CTAB}^{+} \mathrm{TPB}^{-}
$$


Barium ions $\left(\mathrm{Ba}^{2+}\right)$, which are present in the solution, form a pseudoionic complex with EO groups from the nonionic surfactants

$$
\mathrm{Ba}^{2+}+x \mathrm{EONS} \Leftrightarrow\left[\mathrm{Ba}(\mathrm{EONS})_{x}\right]^{2+}
$$

Thus, the reaction of EO-nonionic surfactant with TPB is possible according to:

$$
\left[\mathrm{Ba}(\mathrm{EONS})_{x}\right]^{2+}+2 \mathrm{TPB}^{-} \Leftrightarrow \mathrm{Ba}(\mathrm{EONS})_{x}(\mathrm{TPB})_{2}
$$

Since there is a difference between constants of the solubility of the products between the two ion pairs, the titration curves have two distinct inflexion points (Figure 3). Therefore, all titrations in this study were performed in the solutions containing $\mathrm{Ba}^{2+}$ ions $(0.2 \mathrm{M})$ [3]

The solution of CTAB $\left(2.5 \times 10^{-3} \mathrm{M}\right)$ was used as analyte and TPB $\left(2.5 \times 10^{-3} \mathrm{M}\right)$ as a titrant. The direct potentiometric titration with the new DHBI-TPB surfactant sensor gave the titration curves a high potential change and a sharp inflexion point. Moreover, a series of three nonionic surfactants with different degrees of ethoxylation, namely, a different number of EO groups, were separately used in combination with CTAB as analyte and $\mathrm{TPB}$ as a titrant. The selected nonionic surfactants were Genapol T080 $(2 \mu \mathrm{mol})$ with 8 EO groups, Genapol T110 $(1.5 \mu \mathrm{mol})$ with 11 EO groups and Triton X100 $(2 \mu \mathrm{mol})$ with 10 EO groups. Genapol surfactants were selected since they are often used in commercial product formulations and Triton X100 because it is used as a reference for determining EO-nonionic surfactants in effluents [29].

Figure 3 presents titrations of model samples of cationic surfactant CTAB $\left(2.5 \times 10^{-3} \mathrm{M}\right)$ and three EO-nonionic surfactants that differ in quantity and number of EO groups with TPB $\left(2.5 \times 10^{-3} \mathrm{M}\right)$ as the titrant obtained with the DHBI-TPB surfactant sensor as the end-point detector. As expected, all titration curves exhibited two inflexion points. The first inflexion was obtained because of the CTAB counter ion, and the second was due to the pseudoionic complex of $\mathrm{Ba}^{2+}$ ions and an EO-nonionic surfactant counter ion.

The direct potentiometric titration curves for the CTAB and for model solutions containing CTAB and EO-nonionic surfactants could be compared, and observations made of the extensive influence of the latter to the shape, the inflexion point at first equivalence point and the potential change. However, this effect was not so noticeable, especially when the number of EO groups was increased. The increment of EO groups also resulted in a lower change of the signal potential. The second inflection points were well defined for all EO-nonionic surfactants and were also well-matched with the volumes of the added EO-nonionic surfactants.

Furthermore, the concentration effect on three previously used EO-nonionic surfactants was examined as shown in Figure 3. The experiments were conducted with Genapol T080 $(6.0 \mu \mathrm{mol})$, Genapol T110 $(4.5 \mu \mathrm{mol})$ and Triton X100 (6.0 $\mu \mathrm{mol})$. As shown, compared to the experiments conducted with the lower quantities of EO-nonionic surfactants, the effect of the increased concentration of the EOs number on titration curves was significant. Similar to the first inflexion points, the second were also less sharp, more stretched and with a lower change in potential; however, they were generally more disturbed. The smallest influence on the second inflexion point was observed for Triton X100 $(6.0 \mu \mathrm{mol})$, as the inflexion was almost invisible.

The results confirmed the high influence of the concentration and number of EO groups of nonionic surfactants on cationic surfactants titrations. The higher concentrations of EO-nonionic surfactants were used, and a larger negative influence of the EO-nonionic surfactants was observed. Normally, EO-nonionic surfactant concentrations are less than double in commercial product formulations. Since the concentrations of EO-nonionic surfactants were tripled in the experiments, their expected influence on the shape and size of the cationic surfactant titration curves for the commercial products could be estimated as medium to low. 


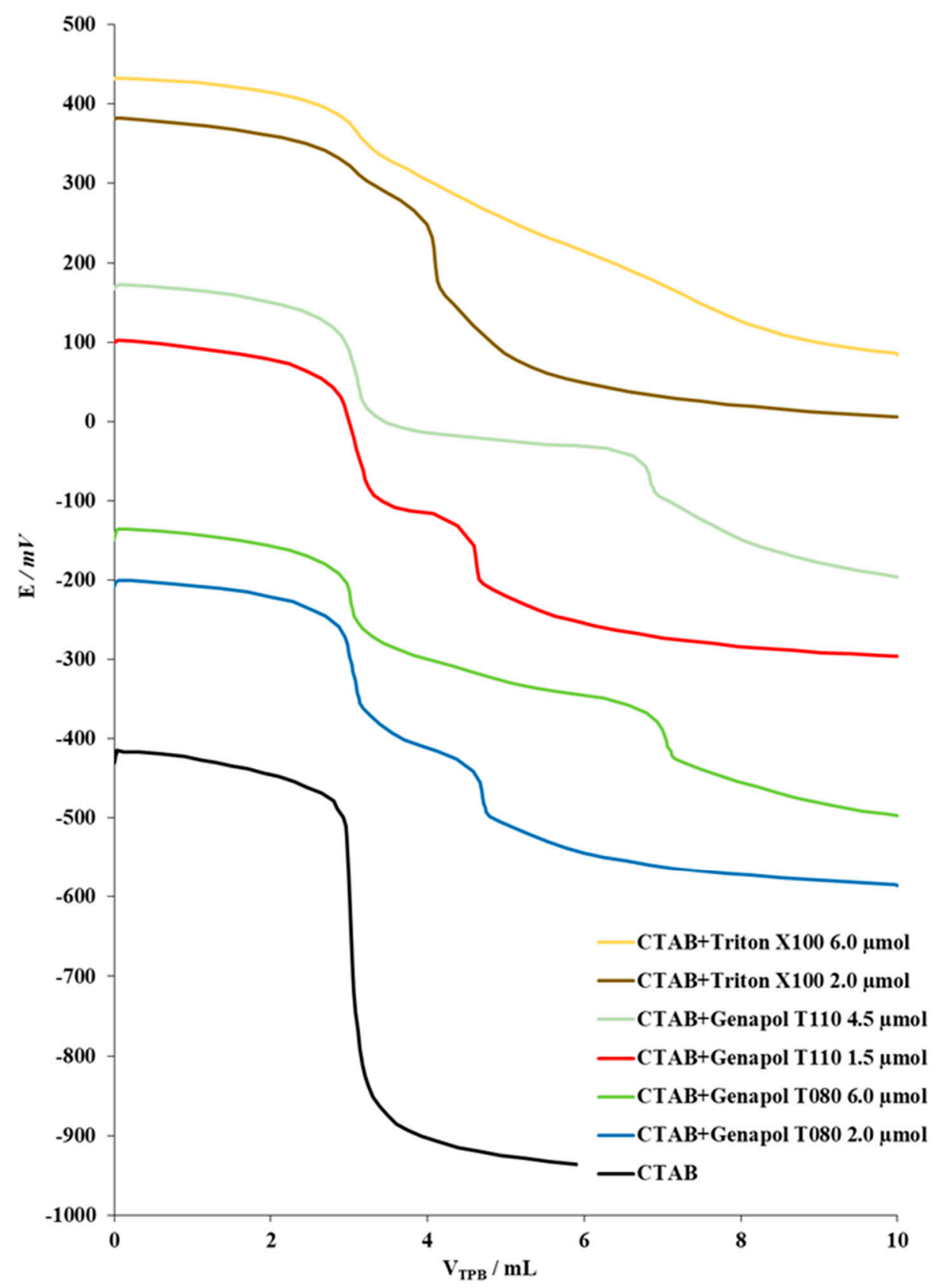

Figure 3. The influence of quantity and number of EO groups for the three EO-nonionic surfactants on the direct potentiometric titration curves of cationic surfactant CTAB $\left(2.5 \times 10^{-3} \mathrm{M}\right)$ and selected EO-nonionic surfactants with TPB $\left(2.5 \times 10^{-3} \mathrm{M}\right)$, in $\mathrm{Ba}^{2+}(0.2 \mathrm{M})$ using the DHBI-TPB surfactant sensor as the end-point detector. The titration curves for corresponding formulations of EO-nonioinic surfactant and CTAB were rearranged in order of appearance for clarity, from the bottom up: (1) only CTAB; (2) CTAB with Genapol T080 $2.0 \mu \mathrm{mol}$; (3) CTAB with Genapol T080 $6.0 \mu \mathrm{mol}$; (4) CTAB with Genapol T110 $1.5 \mu \mathrm{mol}$; (5) CTAB with Genapol T110 $4.5 \mu \mathrm{mol}$; (6) CTAB with Triton X100 $2.0 \mu \mathrm{mol}$ and (7) CTAB with Triton X100 $6.0 \mu \mathrm{mol}$.

\subsubsection{Titration of Commercial Samples}

Direct potentiometric titration of commercial samples using the DHBI-TPB surfactant sensor as the end-point detector was carried out in three directions. The first two were the direct potentiometric titration of a technical-grade cationic surfactant and the direct potentiometric titration of a cationic surfactant for the selected products. Both sets of results were compared with the results obtained by the standard addition method. The 
third concerned the direct potentiometric titration of 10 disinfectants and personal care products. The results were compared with commercial surfactant sensors. For all of these commercial samples, the $\mathrm{pH}$ values were adjusted to between 6 and 9 .

The DHBI-TPB surfactant sensor was applied for direct potentiometric titrations of raw cationic surfactants that were used to produce disinfectants and personal care products. Thus, the experiments were performed with technical-grade CTAB, Hyamine, CPC, benzalkonium chloride (BAC), and didecyldimehtylammonium chloride (DDAC). The quantities of the cationic surfactants were evaluated from the end-point values (five repetitions) obtained by direct potentiometric titrations with DHBI-TPB surfactant sensor and TPB $\left(4 \times 10^{-3} \mathrm{M}\right)$ used as a titrant (Table 3$)$. The results showed that the purity of the employed technical-grade surfactants varied from 95.39 to $98.45 \%$, while BAC and DDAC exhibited the lowest purity as expected. Finally, good agreement between the results obtained by direct potentiometric titration and the standard two-phase titration method [12] was obtained (Table 3).

Table 3. The direct potentiometric titrations of technical-grade cationic surfactants by the DHBI-TPB surfactant sensor compared to a standard two-phase titration method. For direct potentiometric titrations, TPB $\left(4 \times 10^{-3} \mathrm{M}\right)$ was used as a titrant.

\begin{tabular}{lccc}
\hline \multirow{2}{*}{$\begin{array}{c}\text { Technical Grade } \\
\text { Cationic Surfactant }\end{array}$} & \multicolumn{2}{c}{ DHBI-TPB Surfactant Sensor } & Two-Phase Titration \\
\cline { 2 - 4 } & Found (\%) & RSD (\%) & Found (\%) \\
\hline CTAB & 95.39 & 0.59 & 95.89 \\
Hyamine & 98.45 & 0.48 & 98.52 \\
CPC & 97.92 & 0.34 & 98.20 \\
BAC & 51.09 & 0.90 & 50.86 \\
DDAC & 50.97 & 0.61 & 51.43 \\
\hline
\end{tabular}

Further studies of the influence of the matrix were performed by the direct potentiometric titration of a cation surfactant in commercial samples of three mouthwashes and eye drops using the DHBI-TPB surfactant sensor compared to the standard addition method (Table 4). As first, direct potentiometric titrations were employed to detect the quantity of cationic surfactants in commercial products. The DDS $\left(4 \times 10^{-4} \mathrm{M}\right)$ was used as a titrant. The known quantity of CTAB (Table 4) was added to the samples and was titrated by a corresponding concentration of DDS. As presented, the recoveries were calculated from 98 to $102 \%$.

Table 4. The results of the direct potentiometric titrations of the commercial samples with the standard addition method by adding the known quantity of CTAB and by using the DHBI-TPB surfactant sensor as the end-point indicator and DDS $\left(4 \times 10^{-4} \mathrm{M}\right)$ as the titrant.

\begin{tabular}{|c|c|c|c|c|}
\hline \multirow{2}{*}{$\begin{array}{l}\text { Commercial } \\
\text { Sample }\end{array}$} & \multirow{2}{*}{$\begin{array}{l}\text { Calculated Cationic } \\
\text { Surfactant (M) }\end{array}$} & \multicolumn{3}{|c|}{ СТАВ } \\
\hline & & Added (mol) & Found $(\mathrm{mol})^{a}$ & Recovery (\%) \\
\hline Mouthwash 1 & $3.34 \times 10^{-3}$ & $1 \times 10^{-5}$ & $0.98 \times 10^{-5}$ & 98.0 \\
\hline Mouthwash 2 & $3.83 \times 10^{-3}$ & $7 \times 10^{-5}$ & $7.11 \times 10^{-5}$ & 101.6 \\
\hline Mouthwash 3 & $1.40 \times 10^{-3}$ & $3 \times 10^{-4}$ & $3.06 \times 10^{-5}$ & 102.0 \\
\hline Eye drops 1 & $6.26 \times 10^{-4}$ & $5 \times 10^{-5}$ & $5.03 \times 10^{-5}$ & 100.6 \\
\hline
\end{tabular}

In Figure 4 shows titration curves of the direct potentiometric titrations of cationic surfactants in commercial samples of mouthwash (Mouthwash 3) with and without added $\mathrm{CTAB}$ of known concentration and compares them with a titration of pure CTAB. DDS $\left(5 \times 10^{-4} \mathrm{M}\right)$ was used as the titrant. The aim of Figure 4 is to compare the pure CTAB titration curve--high signal change, well-defined inflexion point, sharp and narrow first derivative, and clear end-point value (green line)--with the titration curve of the complex matrix in a commercial product containing a cationic surfactant--lower signal change, 
less-defined inflexion points and a broader first derivative curve, but still with a clear end-point value (black line).

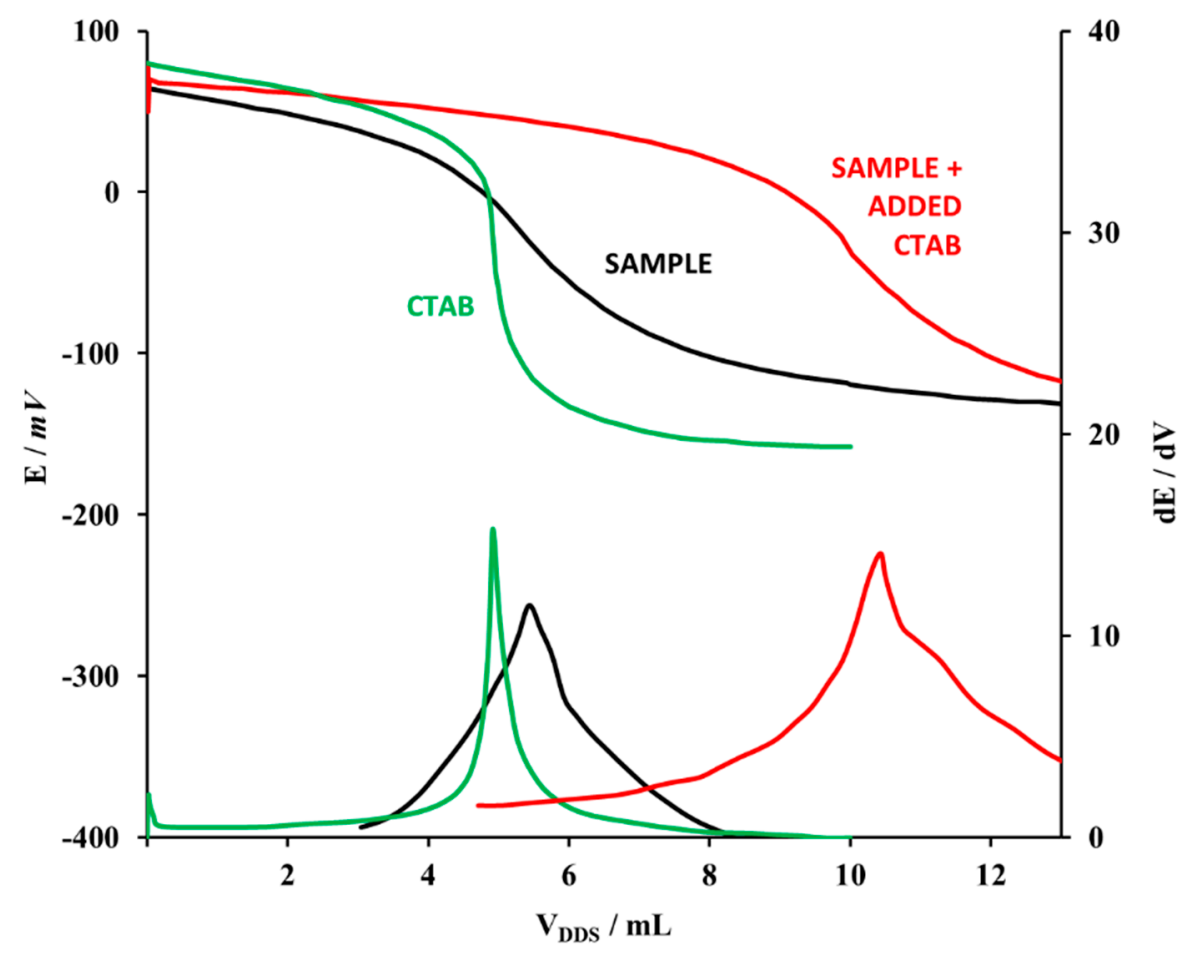

Figure 4. Direct potentiometric titration curves of (1) the commercial sample of the mouthwash 3 (black line); (2) CTAB $\left(5 \times 10^{-4} \mathrm{M}\right)$ sample (green line); and (3) the same sample of mouthwash 3 with known addition of CTAB (red line); and their corresponding first derivatives. DDS $\left(5 \times 10^{-4} \mathrm{M}\right)$ was used as the titrant.

After a known amount of $\mathrm{CTAB}$ was added to the sample, the end point was shifted for the corresponding equimolar volume of the DDS titrant. This proved that the sample matrix had no influence on the end-point detection, which was observed for all examined samples as presented in Table 4 .

Twelve commercial disinfectants and personal care products were tested on cationic surfactants by direct potentiometric titration by using the DHBI-TPB surfactant sensor as the end-point indicator and TPB as a titrant as summarized in Table 5.

The $\mathrm{pH}$ values were adjusted between 3 and 9. The highest amounts of cationic surfactants were detected in both disinfectants for hospitals samples, 4.1032 and $5.0964 \%$, respectively. In the mouthwash samples, cation surfactant amounts were much lower than in disinfectants for hospitals, ranging from 0.0480 to $0.1882 \%$, respectively. In medical skindisinfectant samples, cation surfactant amounts ranged from 0.1998 to $0.3769 \%$. The lowest amounts of cationic surfactants were detected in all four nose drops samples where cation surfactant amounts found were in the range from 0.0099 to $0.0178 \%$. The results showed an excellent agreement with the referent commercial surfactant sensor and a two-phase titration method results. 
Table 5. The results of direct potentiometric titrations of twelve commercially available disinfectants and personal care products containing cationic surfactants using the TPB $\left(5 \times 10^{-3} \mathrm{M}\right)$ as a titrant and DHBI-TPB surfactant sensor as the end-point indicator. The results were compared with the results obtained from the commercial surfactant sensor and a referent two-phase titration method.

\begin{tabular}{|c|c|c|c|c|c|c|}
\hline \multirow[t]{2}{*}{ Type Of Commercial Product } & \multicolumn{3}{|c|}{ DHBI-TPB Surfactant Sensor ${ }^{a}$} & \multicolumn{2}{|c|}{$\begin{array}{c}\text { Commercial } \\
\text { Surfactant Sensor }\end{array}$} & \multirow{2}{*}{$\begin{array}{l}\text { Two Phase } \\
\text { Titration } \\
\text { Found } \%\end{array}$} \\
\hline & Found $\%$ & RSD(\%) & Confidence Interval $( \pm)$ & Found $\%$ & RSD(\%) & \\
\hline Mouthwash 1 & 0.1137 & 0.74 & 0.000743 & 0.1151 & 0.76 & 0.1143 \\
\hline Mouthwash 2 & 0.1303 & 1.06 & 0.001216 & 0.1297 & 1.12 & 0.1311 \\
\hline Mouthwash 3 & 0.0480 & 1.49 & 0.000630 & 0.0480 & 1.39 & 0.0462 \\
\hline Mouthwash 4 & 0.1882 & 0.34 & 0.000560 & 0.1888 & 0.39 & 0.1821 \\
\hline Medical skin disinfectant 1 & 0.1998 & 1.27 & 0.002231 & 0.1984 & 1.32 & 0.1993 \\
\hline Medical skin disinfectant 2 & 0.3769 & 0.91 & 0.000788 & 0.3639 & 0.89 & 0.3649 \\
\hline Disinfectant for hospitals 1 & 4.1032 & 0.97 & 0.001862 & 4.1005 & 0.91 & 4.1025 \\
\hline Disinfectant for hospitals 2 & 5.0964 & 0.51 & 0.000982 & 5.0979 & 0.78 & 5.1002 \\
\hline Nose drops 1 & 0.0150 & 1.76 & 0.000232 & 0.0152 & 1.06 & 0.0142 \\
\hline Nose drops 2 & 0.0151 & 2.07 & 0.000275 & 0.0160 & 1.90 & 0.0156 \\
\hline Nose drops 3 & 0.0099 & 1.49 & 0.000129 & 0.0102 & 1.67 & 0.0101 \\
\hline Nose drops 4 & 0.0178 & 1.67 & 0.000261 & 0.0185 & 1.73 & 0.0180 \\
\hline
\end{tabular}

${ }^{a}$ Average of five measurements. ${ }^{b}$ Average of three measurements.

\section{Materials and Methods}

\subsection{Reagents and Materials}

Materials and reagents used for this organic synthesis were all analytical-grade chemicals: 1-bromohexadecane, with $1 \mathrm{H}$-1,3-benzimidazole and $\mathrm{NaHCO}_{3}$ (Sigma Aldrich, Darmstadt, Germany). These chemicals were used in the experiments without any additional purification. Ultrapure water was used to prepare the solutions.

To conduct response characterizations and titrations, analytical-grade cationic surfactants were used: cetylpyridinium chloride (CPC) (Merck, Darmstadt, Germany); Hyamine 1622 (Hyamine) (Fluka, Buchs, Switzerland), hexadecyltrimethylammonium bromide (CTAB) (Fluka, Buchs, Switzerland) whereas cationic surfactants: benzalkonium chloride (BAC) and-didecyldimethylammonium chloride (DDAC) were technical grade. Anionic surfactant DDS (Fluka, Buchs, Switzerland) was used for the dynamic response and titrants were of an analytical grade. Nonionic surfactants, Genapol T 080 and Genapol T 110 were a technical-grade (Clariant, Switzerland) while Triton X-100 (Merck, Darmstadt, Germany) was analytical grade.

Na-TPB (Fluka, Buchs, Switzerland) was used for the response measurements and as a titrant for a pseudoionic complex with barium chloride (Fluka, Buchs, Switzerland).

For the membrane preparation, a high-molecular weight PVC (Sigma Aldrich, Darmstadt, Germany), a plasticizer o-nitrophenyloctylether (o-NPOE) (Sigma Aldrich, Darmstadt, Germany) and tetrahydrofuran (THF) (Merck, Darmstadt, Germany) analytical-grade chemicals were used.

\subsection{Synthesis of Quaternary Alkyl Ammonium Salt 1}

A novel quaternary alkyl ammonium salt DHBI-Br 1 was synthesized by reacting 1bromohexadecane with $1 \mathrm{H}-1,3$-benzimidazole. In a $25 \mathrm{~mL}$ round-bottomed flask equipped with a magnetic stir bar, $1 \mathrm{H}-1,3$-benzimidazole $(0.312 \mathrm{~g}, 2.64 \mathrm{mmol})$ and $\mathrm{NaHCO}_{3}(0.887 \mathrm{~g}$, $10.56 \mathrm{mmol})$ in anhydrous dimethylformamide $(15 \mathrm{~mL})$ were dissolved. The resulting mixture was then stirred at $110{ }^{\circ} \mathrm{C}$ for $1 \mathrm{~h}$ in an inert atmosphere. After cooling the mixture to ambient temperature, an excess of 1-bromohexadecane $(4.84 \mathrm{~g}, 15.84 \mathrm{mmol})$ was added, and the resulting mixture was again heated under reflux for $48 \mathrm{~h}$. The progress of the reaction was followed by TLC $(\mathrm{DCM} /$ methanol $=10: 0.25)$. The desired crude product 1 was obtained in high purity via filtration of the precipitated inorganic salts with methanol followed by filtration of the resulting waxy residue with hexane. This was followed 
by the flash column purification $(\mathrm{DCM} /$ methanol $=10: 0.25)$ and drying under reduced pressure. The white powder bisalkylated DHBI-Br $1(0.941 \mathrm{~g}, 1.66 \mathrm{mmol})$ was obtained in a $62.7 \%$ yield.

The structure of the synthesized DHBI-Br 1 was confirmed by IR, ${ }^{1} \mathrm{H}$ - and ${ }^{13} \mathrm{C}-\mathrm{NMR}$ spectroscopy, mass spectrometry and elemental analysis. A detailed analysis can be found in the Supplementary Materials (Figures S1-S4).

\subsection{Characterization of Quaternary Alkyl Ammonium Salt}

\subsubsection{FTIR}

IR spectra were recorded on a Shimadzu IR solution 1.30 FTIR-8400 S infrared spectrophotometer.

\subsubsection{NMR}

${ }^{1} \mathrm{H}$ NMR spectra were recorded at $600 \mathrm{MHz}$ and ${ }^{13} \mathrm{C}$ NMR spectra at $150.9 \mathrm{MHz}$ using a Bruker AV600 spectrometer (Rheinstetten, Germany) at Ruđer Bošković Institute. Chemical shifts were referenced for the residual solvent peak (DMSO-d6) with $\mathrm{SiMe}_{4}$ as the internal standard.

\subsubsection{LC-MS}

Spectroscopic information on the molecular ions was obtained through the API 2000 LC-ESI-MS/MS (Applied Biosystems, Foster City, CA, USA) in q1 ms scan mode.

\subsubsection{Elemental Analysis}

For the elemental analysis PerkinElmer 2400 CHNS/O Series II System was used (PerkinElmer Inc., Waltham, MA, USA).

\subsection{Preparation of DHBI-TPB Surfactant Sensor}

\subsubsection{Preparation of DHBI-TPB 2 Ion-Pair Sensing Complex}

For the ion-pair preparation, newly synthetized DHBI-Br $\mathbf{1}$ was used as a source of the cation and Na-TPB was used as a resource of a counter-ion. The mixture of an aqueous solution of Na-TPB $(0.05 \mathrm{M})$ and ethanol/water solution (volume ratio 2:1) of DHBI-Br 1 was heated to $50{ }^{\circ} \mathrm{C}$. The hot Na-TPB solution $10 \mathrm{~mL}$ was slowly added to the $30 \mathrm{~mL}$ of a hot DHBI-Br solution in ethanol-water containing equimolar quantity of DHBI-Br 1 . The opaque reaction mixture was stirred and heated. At $70{ }^{\circ} \mathrm{C}$ the mixture become transparent and the white precipitate appeared at $80^{\circ} \mathrm{C}$. After removing the white precipitate and evaporating the ethanol, the crude DHBI-TPB 2 salt was washed, filtrated, and dried at $80^{\circ} \mathrm{C}$. When the mass of the DHBI-TPB 2 was constant, it was stored in a desiccator and used for sensor membrane preparation.

\subsubsection{Sensor Membrane Preparation}

The sensor membrane cocktail consisting of 33\% high-molecular weight $\mathrm{PVC}, 66 \%$ plasticizer o-NPOE, and 1\% prepared DHBI-TPB ion-pair 2 was prepared. The sensor membrane was made by the following procedure: $0.1 \mathrm{~g}$ of the above-described mixture was added to $2 \mathrm{~mL}$ of THF and sonicated for $15 \mathrm{~min}$; the sensor membrane cocktail was slowly poured onto the borosilicate glass-ring mold fixed to the glass plate and left to dry. Upon drying, the glass ring was removed and the membrane was cut into smaller circular pieces to fit the electrode body.

\subsubsection{Surfactant Sensor Preparation}

The cut sensor membrane was fixed to the Philips electrode body IS-561 (Supelco, Bellefonte, PA, USA) filled with $\mathrm{NaCl}(3 \mathrm{M})$ as an inner electrolyte. The obtained DHBI-TPB surfactant sensor was used for further studies. 


\subsection{Apparatus}

Response, dynamic response, and interference measurements were carried out by Metrohm 794 Basic Titrino paired with a Metrohm $781 \mathrm{pH}$ meter and corresponding stirrer. The system was controlled by home-developed software.

The titration measurements were carried out by Metrohm 808 Titrando equipped with an incorporated stirrer. The system was controlled by Metrohm Tiamo software. For the $\mathrm{pH}$ adjustments, a Metrohm $781 \mathrm{pH}$ meter paired with a Metrohm $\mathrm{pH}$ electrode was used. As a reference electrode was used, a Metrohm silver/silver (I) chloride electrode with a potassium chloride ( $3 \mathrm{M}$ ) electrolyte.

\subsection{Procedure}

For the described studies a prepared DHBI-TPB surfactant sensor paired with a reference electrode was used. The distilled water was employed for rinsing electrodes between measurements.

\subsubsection{Direct Potentiometric Sensor Characterization}

The response measurements of DHBI-TPB surfactant sensor were performed by the incremental addition of cationic surfactants CTAB, CPC and Hyamine in deionized water. The concentrations of the cationic surfactants ranged from $5 \times 10^{-4} \mathrm{M}$ to $5 \times 10^{-5} \mathrm{M}$, which corresponds to the logarithmic concentration area from approximately -2 to -8 . The dynamic response measurements of DHBI-TPB surfactant sensor to TPB and DDS anions were performed using the activity step method according to IUPAC [30]. To reach certain concentrations, determined quantities of TPB and DDS anions were added to deionized water and gave a dynamic response, The speed of the response and sensor stabilization time were measured.

Interference measurements were performed by the incremental addition of $\mathrm{CTAB}$ in selected interfering cation solutions $(0.01 \mathrm{M})$. The concentrations of CTAB were $5 \times 10^{-4} \mathrm{M}$ and $5 \times 10^{-5} \mathrm{M}$ to cover the logarithmic concentration area from approximately -2 to -8 . The fixed interference method, as proposed by IUPAC [31], was used to determine the potentiometric selectivity coefficients.

The influence of the $\mathrm{pH}$ on the DHBI-TPB surfactant sensor response towards CTAB $(0.5 \mathrm{mM})$ in deionized water and CTAB $(0.5 \mathrm{mM})$ in $\mathrm{Na}_{2} \mathrm{SO}_{4}(0.1 \mathrm{M})$ was observed within the range of $\mathrm{pH} 2-13 . \mathrm{Na}_{2} \mathrm{SO}_{4}$ was used to observe the influence of the high ionic strength. The corresponding $\mathrm{pH}$ values were adjusted with $\mathrm{HCl}(0.5 \mathrm{M})$ and $\mathrm{NaOH}(0.5 \mathrm{M})$.

The deionized water was used for sensor storage. For the elemental analysis PerkinElmer 2400 CHNS/O Series II System was used (PerkinElmer Inc., Waltham, MA, USA).

\subsubsection{Direct Potentiometric Titrations}

Direct potentiometric titrations were performed in the dynamic equivalent-point titration mode. The signal drift was set to $5 \mathrm{mV} / \mathrm{min}$. Between the measurements, electrodes were rinsed with distilled water. The direct potentiometric titrations of cationic surfactants with DHBI-TPB surfactant sensor were measured in two directions; (a) to examine the influence of nonionic surfactants on CTAB titrations, and (b) to titrate cationic surfactants in commercial samples.

To check the influence of nonionic surfactants amount and number of EO-nonionic surfactant groups on the direct potentiometric titrations of mixtures containing CTAB and a selected nonionic surfactant, a series of three nonionic surfactants containing different numbers of EO groups was separately prepared and used in combination with CTAB and TPB as a titrant. The studied nonionic surfactants were Genapol T080 with 8 EO groups, Triton X100 with 10 EO groups and Genapol T110 with 11 EO groups, in two concentration series. These measurements were performed in $0.2 \mathrm{M} \mathrm{Ba}^{2+}$ solutions which was necessary to form a pseudoionic complex of $\mathrm{Ba}^{2+}$ with nonionic surfactants (3) that could be titrated with TPB solutions (buffered with borate buffer solution at $\mathrm{pH} 10.0$ ). 
The concentrations of cationic surfactants in commercial disinfectants and personal care products were measured with DHBI-TPB surfactant sensor by the direct potentiometric titrations of raw industrial cationic surfactant samples and 12 commercial samplesmouthwash, eye drops, nose drops, medical skin disinfectant, and hospital disinfectantthat were purchased from local drugstores.

The standard addition method was used to establish the matrix influence on end-point detection and for the determination of accuracy, precision, and matrix influence. A twophase titration was used as an official reference method for the cationic surfactants. [12]. Three repetitive measurements were performed.

\section{Conclusions}

A new cationic surfactant DHBI-Br 1 was successfully synthesized and characterized by NMR, FTIR, LC-MS and elemental analysis. The exchange of a counter-ion of DHBI-Br 1 created the new ionophore DHBI-TPB 2, which was employed to develop the new PVCbased DHBI-TPB direct potentiometric surfactant sensor. This device presented excellent response characteristics to $\mathrm{CTAB}, \mathrm{CPC}$ and Hyamine with a Nernstian slope from 57.1 to $59.1 \mathrm{mV} /$ decade. The broadest useful linear concentration range was presented for CTAB, $2.0 \times 10^{-6}$ to $1.0 \times 10^{-4} \mathrm{M}$, with the lowest LOD of $0.3 \times 10^{-6} \mathrm{M}$. Dynamic responses of DDS and TPB in the range of $1 \times 10^{-6}$ to $1 \times 10^{-3} \mathrm{M}$ showed fast sensor response and a stable signal. Inorganic and organic cations that are usually found in commercial product formulations showed no significant influence on the DHBI-TPB surfactant sensor response towards $\mathrm{CTAB}$. A pH from 2 to 11 did not influence the measurements in the range. Direct potentiometric titrations of cationic surfactants and nonionic surfactants in model formulations exhibited two inflexion points. The first was obtained because of the CTAB counter ion and the second because of to the pseudoionic complex of $\mathrm{Ba}^{2+}$ ions and EO-nonionic surfactant counter-ion. An increased number of EO groups ( 9 to 11) had an extensive negative influence on to the titration curve shape, inflexion point at the first equivalence point, and the potential change. The increased concentration of EO-nonionic surfactants showed a negative influence on titration curves at the first but also at the second inflexion point. The results of the direct potentiometric titrations of raw cationic surfactants-CTAB, Hyamine, CPC, BAC, DDAC-that were used in the production of disinfectants and personal care products, showed good agreement with a reference two-phase titration method. The standard addition method was successfully applied to commercial samples of mouthwash and eye drops containing cationic surfactants and showed recoveries from 98 to $102 \%$. The results of direct potentiometric titrations of 12 commercially available disinfectants and personal care products containing cationic surfactants showed good agreement with the results obtained by the employment of a commercial surfactant sensor. As presented, the DHBI-TPB direct potentiometric surfactant sensor is cheap, simple, robust and user-friendly. Therefore, it presents an excellent new alternative for the routine analysis of cationic surfactants in commercial samples. Further studies on multicomponent mixtures containing cationic surfactants and nonionic surfactants are in progress.

Supplementary Materials: The following are available online, Figures S1 to S4: titles as indicated in Table of Contents.

Author Contributions: Conceptualization, M.J. and N.S.; Methodology, M.J., N.S.; Formal Analysis, D.M.-Č., N.S., D.M. and M.J.; Investigation, M.J. and N.S.; Resources, M.J., N.S., B.Š., K.H., and B.S.; Data Curation, N.S., D.M. and M.J.; Writing-Original Draft Preparation, N.S., M.J., D.M.-Č., B.Š. and K.H.; Writing-Review \& Editing, N.S., D.M. and M.J.; Visualization, B.Š., K.H. and B.S.; Supervision, M.J. and N.S.; Project Administration, M.J. and N.S. All authors have read and agreed to the published version of the manuscript.

Funding: D.M. would like to thank the Croatian Science Foundation for funding the research project IP-2019-04-8846 and to the University of Rijeka for funding the research grant UNIRIprirod $-18-102$. 
Institutional Review Board Statement: Not applicable.

Informed Consent Statement: Not applicable.

Data Availability Statement: The data presented in this study are available in Supplementary Materials.

Acknowledgments: Authors thank the EuChemS Sample Preparation Task Force and Network and the COST Action PortASAP-European network for the promotion of portable, affordable and simple analytical platforms.

Conflicts of Interest: The authors declare no conflict of interest.

Sample Availability: All samples are available from the authors.

\section{References}

1. Jozanović, M.; Sakač, N.; Karnaš, M.; Medvidović-Kosanović, M. Potentiometric Sensors for the Determination of Anionic Surfactants-A Review. Crit. Rev. Anal. Chem. 2019, 1-23. [CrossRef] [PubMed]

2. Research and Markets Surfactants Market by Type (Anionic, Non-Ionic, Cationic, and Amphoteric), Application (Home Care, Personal Care, Industrial \& Institutional Cleaning, Textile, Elastomers \& Plastics, Agrochemicals, and Food E Beverage), Region-Global Forecast to 2025; Pune, India, 2020. Available online: https://www.researchandmarkets.com/reports/3927849/surfactants-market-by-typeanionic-non-ionic (accessed on 12 December 2020).

3. Sak-Bosnar, M.; Madunić-Čačić, D.; Sakač, N.; Galović, O.; Samardžić, M.; Grabarić, Z. Potentiometric Sensor for Polyethoxylated Nonionic Surfactant Determination. Electrochim. Acta 2009, 55, 528-534. [CrossRef]

4. Ogino, K.; Abe, M. (Eds.) Mixed Surfactant Systems; Marcel Dekker, Inc.: New York, NY, USA, 1993.

5. Kawai, R.; Niki, M.; Yada, S.; Yoshimura, T. Surface Adsorption Properties and Layer Structures of Homogeneous PolyoxyethyleneType Nonionic Surfactants in Quaternary-Ammonium-Salt-Type Amphiphilic Gemini Ionic Liquids with Oxygen- or NitrogenContaining Spacers. Molecules 2020, 25, 4881. [CrossRef] [PubMed]

6. Natsheh, H.; Touitou, E. Phospholipid Vesicles for Dermal/Transdermal and Nasal Administration of Active Molecules: The Effect of Surfactants and Alcohols on the Fluidity of Their Lipid Bilayers and Penetration Enhancement Properties. Molecules 2020, 25, 2959. [CrossRef]

7. Research and Markets Global Surfactants Market (2019 to 2025)_Drivers, Restraints, Opportunities and Challenges; Pune, India, 2020. Available online: https:/ / www.prnewswire.com/news-releases/global-surfactants-market-2019-to-2025---drivers-restraintsopportunities-and-challenges-301086922.html (accessed on 12 December 2020).

8. Samara, F.; Badran, R.; Dalibalta, S. Are Disinfectants for the Prevention and Control of COVID-19 Safe? Health Secur. 2020, 18, 496-498. [CrossRef] [PubMed]

9. Zheng, G.; Filippelli, G.M.; Salamova, A. Increased Indoor Exposure to Commonly Used Disinfectants during the COVID-19 Pandemic. Environ. Sci. Technol. Lett. 2020, 7, 760-765. [CrossRef]

10. Fizer, M.; Fizer, O.; Sidey, V.; Mariychuk, R.; Studenyak, Y. Experimental and Theoretical Study on Cetylpyridinium Dipicrylamide-A Promising Ion-Exchanger for Cetylpyridinium Selective Electrodes. J. Mol. Struct. 2019, 1187, 77-85. [CrossRef]

11. Hrenovic, J.; Ivankovic, T. Toxicity of Anionic and Cationic Surfactant to Acinetobacter Junii in Pure Culture. Open Life Sci. 2007, 2, 405-414. [CrossRef]

12. Reid, V.; Longman, G.; Heinerth, E. Determination of Anionic-Active Detergents by Two-Phase Titration. Tenside Deterg. 1967, 4, 292-304.

13. Miller, C.; Bageri, B.S.; Zeng, T.; Patil, S.; Mohanty, K.K. Modified Two-Phase Titration Methods to Quantify Surfactant Concentrations in Chemical-Enhanced Oil Recovery Applications. J. Surfactants Deterg. 2020, 23, 1159-1167. [CrossRef]

14. Yang, D.; Wang, Y.; Wang, Y.; Li, H. A Simple and Effective Luminescence Sensor Distinguishing Cationic Surfactants from Other Type of Surfactants. Sens. Actuators B Chem. 2016, 235, 206-212. [CrossRef]

15. Olkowska, E.; Polkowska, Ż.; Namieśnik, J. A Solid Phase Extraction-Ion Chromatography with Conductivity Detection Procedure for Determining Cationic Surfactants in Surface Water Samples. Talanta 2013, 116, 210-216. [CrossRef]

16. Wang, D.-E.; Zhao, L.; Yuan, M.-S.; Chen, S.-W.; Li, T.; Wang, J. Fabrication of Polydiacetylene Liposome Chemosensor with Enhanced Fluorescent Self-Amplification and Its Application for Selective Detection of Cationic Surfactants. ACS Appl. Mater. Interfaces 2016, 8, 28231-28240. [CrossRef]

17. Makarova, N.M.; Kulapina, E.G. New Potentiometric Sensors Based on Ionic Associates of Sodium Dodecylsulfate and Cationic Complexes of Copper(II) with Some Organic Reagents. Electroanalysis 2015, 27, 621-628. [CrossRef]

18. Matešic-Puac, R.; Sak-Bosnar, M.; Bilic, M.; Grabaric, B.S. New Ion-Pair Based All-Solid-State Surfactant Sensitive Sensor for Potentiometric Determination of Cationic Surfactants. Electroanalysis 2004, 16, 843-851. [CrossRef]

19. Pechenkina, I.A.; Mikhelson, K.N. Materials for the Ionophore-Based Membranes for Ion-Selective Electrodes: Problems and Achievements (Review Paper). Russ. J. Electrochem. 2015, 51, 93-102. [CrossRef] 
20. Sakač, N.; Karnaš, M.; Jozanović, M.; Medvidović-Kosanović, M.; Martinez, S.; Macan, J.; Sak-Bosnar, M. Determination of Anionic Surfactants in Real Samples Using a Low-Cost and High Sensitive Solid Contact Surfactant Sensor with MWCNTs as the Ion-to-Electron Transducer. Anal. Methods 2017, 9, 2305-2314. [CrossRef]

21. Najafi, M.; Maleki, L.; Rafati, A.A. Novel Surfactant Selective Electrochemical Sensors Based on Single Walled Carbon Nanotubes. J. Mol. Liq. 2011, 159, 226-229. [CrossRef]

22. Sánchez Arribas, A.; Moreno, M.; González, L.; Blázquez, N.; Bermejo, E.; Zapardiel, A.; Chicharro, M. A Comparative Study of Carbon Nanotube Dispersions Assisted by Cationic Reagents as Electrode Modifiers: Preparation, Characterization and Electrochemical Performance for Gallic Acid Detection. J. Electroanal. Chem. 2020, 857, 113750. [CrossRef]

23. Olkowska, E.; Polkowska, Z.; Namieśnik, J. Analytics of Surfactants in the Environment: Problems and Challenges. Chem. Rev. 2011, 111, 5667-5700. [CrossRef] [PubMed]

24. Madunić-Čačić, D.; Sak-Bosnar, M. Investigation of Homologous Tallow Fatty Alcohols and Oleyl Alcohol Ethoxylates Using a Potentiometric Surfactant Sensor. Int. J. Electrochem. Sci. 2011, 6, 1630-1641.

25. Madunić Čačić, D.; Sak-Bosnar, M.; Galović, O.; Sakač, N.; Matešić-Puač, R. Determination of Cationic Surfactants in Pharmaceutical Disinfectants Using a New Sensitive Potentiometric Sensor. Talanta 2008, 76, 259-264. [CrossRef]

26. Samardžić, M.; Sak-Bosnar, M.; Madunić-Čačić, D. Simultaneous Potentiometric Determination of Cationic and Ethoxylated Nonionic Surfactants in Liquid Cleaners and Disinfectants. Talanta 2011, 83, 789-794. [CrossRef]

27. Mohamed, G.G.; Ali, T.A.; El-Shahat, M.F.; Al-Sabagh, A.M.; Migahed, M.A.; Khaled, E. Potentiometric Determination of Cetylpyridinium Chloride Using a New Type of Screen-Printed Ion Selective Electrodes. Anal. Chim. Acta 2010, 673, 79-87. [CrossRef] [PubMed]

28. Fizer, O.; Fizer, M.; Sidey, V.; Studenyak, Y. Predicting the End Point Potential Break Values: A Case of Potentiometric Titration of Lipophilic Anions with Cetylpyridinium Chloride. Microchem. J. 2021, 160, 105758. [CrossRef]

29. ISO7875-2:1984. Water Quality_Determination of Surfactants—Part 2: Determination of Non-Ionic Surfactants Using Dragendorff Reagent; ISO/TC 147/SC 2. Physical, Chemical and Biochemical Methods, ICS: 13.060.50. Examination of Water for Chemical Substances; International Organization for Standardization: Geneva, Switzerland, 1984.

30. Lindner, E.; Tóth, K.; Pungor, E. Definition and Determination of Response Time of Ion Selective Electrodes. Pure Appl. Chem. 1986, 58, 469-479. [CrossRef]

31. Buck, R.P.; Lindner, E. Recomendations for Nomenclature of Ion-Selective Electrodes (IUPAC Recommendations 1994). Pure Appl. Chem. 1994, 66, 2527-2536. [CrossRef] 